\title{
Caracterização molecular de variedades crioulas de abóboras com marcadores microssatélites
}

\author{
Daniela Priori ${ }^{1}$; Rosa Lía Barbieri²; Caroline M Castro² ${ }^{2}$ Antonio C de Oliveira ${ }^{1}$; Juliana CB Vilella ${ }^{2}$; \\ Claudete C Mistura ${ }^{1}$ \\ ${ }^{1}$ UFPel, C. Postal 354, 96010-900 Pelotas-RS; dani_priori@yahoo.com.br; acosta@ufpel.edu.br; c.mistura@gmail.com; 2Embrapa \\ Clima Temperado, C. Postal 403 96010-971 Pelotas-RS; lia.barbieri@cpact.embrapa.br; caroline.castro@cpact.embrapa.br; \\ jcbrancov@gmail.com
}

\section{RESUMO}

Dentre as cinco espécies de abóboras domesticadas, Cucurbita pepo apresenta a maior variabilidade para características de fruto, como cor, formato e tamanho. O Banco Ativo de Germoplasma de Cucurbitáceas da Embrapa Clima Temperado conta com 61 acessos desta espécie, todos estes, variedades crioulas cultivadas no sul do Brasil. Estas variedades crioulas fazem parte da cultura regional, na gastronomia, no artesanato e na ornamentação de ambientes. $\mathrm{O}$ objetivo deste trabalho foi avaliar a variabilidade genética entre e dentro de variedades crioulas de C. pepo cultivadas no Rio Grande do Sul, utilizando marcadores microssatélites. Foram avaliados 10 acessos de variedades crioulas de C. pepo. que apresentavam diferentes formatos e tamanhos de fruto, cores e texturas da casca. O DNA genômico foi extraído individualmente de cinco plantas de cada acesso. Foram analisados 40 locos de microssatélites. Destes, 34 amplificaram, identificando 100 alelos (variação de um a cinco alelos por loco). Dos locos analisados $85,3 \%$ foram polimórficos, evidenciando a variabilidade genética entre os acessos. A análise molecular da variância mostrou que $45,39 \%$ da variabilidade genética é atribuída à variação dentro dos acessos e 54,60\% a diferenças entre acessos. Assim, apesar de haver variabilidade genética dentro dos acessos, a maior proporção da variabilidade em C. pepo encontra-se distribuída entre as diferentes variedades crioulas. A variação dentro dos acessos é explicada pela alogamia da espécie, pelo intercâmbio de sementes das variedades crioulas entre os agricultores e também pelos mesmos cultivarem mais de uma variedade de Cucurbita na mesma área.

Palavras-chave: Cucurbita pepo, Cucurbitaceae, divergência genética, recursos genéticos, marcadores moleculares.

\section{ABSTRACT}

\author{
Molecular characterization of pumpkin landraces by \\ microsatellite markers
}

Among the five cultivated species of pumpkins, Cucurbita pepo has the highest variability for fruit characteristics, such as color, shape and size. The Active Germplasm Bank of Cucurbitaceae from Embrapa Clima Temperado (Brazil) has 61 accessions of this species, all of them landraces grown in southern Brazil. These landraces are part of regional culture, in gastronomy (preparation of traditional dishes) for crafts and ornaments. The aim of this study was to evaluate genetic variability within and among landraces of C. pepo cultivated in Rio Grande do Sul state, by microsatellite markers. Ten accessions of $C$. pepo landraces with different shapes and sizes of fruit, and colors and textures of fruit skin were evaluated. Genomic DNA was extracted individually from five plants of each accession. Forty microsatellite loci were analyzed, and 34 amplified. In total 100 alleles were found (one to five alleles per locus). From the analysed loci, $85.3 \%$ were polymorphic, showing the presence of genetic variability among the accessions. The analysis of molecular variance showed that $45.39 \%$ of genetic variability is attributed to differences within accessions, and $54.60 \%$ is attributable to variation among accessions. Thus, despite the presence of genetic variability within accessions, the largest proportion of variability in C. pepo is distributed among the accessions. The genetic variability found within accessions can be due to the allogamy, the exchange of landraces seeds between the farmers and also by cultivation of more than one Cucurbita landrace in the same area.

Keywords: Cucurbita pepo, Cucurbitaceae, genetic diversity, genetic resources, molecular markers.

\section{(Recebido para publicação em 8 de dezembro de 2011; aceito em 31 de julho de 2012)} (Received on December 8, 2011; accepted on July 31, 2012)

$\mathrm{V}$ ariedades crioulas das cinco espécies domesticadas de abóboras (Cucurbita argyrosperma, Cucurbita ficifolia, Cucurbita maxima, Cucurbita moschata e Cucurbita pepo) são cultivadas no Brasil, sendo estas conhecidas por uma grande diversidade de nomes populares, particulares ou em comum (Heiden et al., 2007) A maioria destas variedades é cultivada em pequenas áreas, para o consumo na propriedade e comercialização em mercados locais. Os agricultores realizam a própria seleção de frutos, utilizando as sementes para o cultivo do ano seguinte. Por usarem suas próprias sementes, as quais são resultantes de uma seleção continuada, os agricultores obtêm tipos de frutos muito diversos, os quais são recursos genéticos de grande valor (Ramos \& Queiroz, 2005). Esse processo resulta em populações bastante adaptadas às condições locais de cultivo, que são fonte de genes para tolerância a estresses bióticos e abióticos. Como os agricultores geralmente cultivam mais de uma variedade crioula de abóboras na mesma propriedade, próximas umas das outras, e as espécies de Cucurbita são alógamas, pode ocorrer o cruzamento entre elas, ampliando ainda mais a variabilidade genética existente (Heiden et al., 2007).

A maior diversidade genética de Cucurbita sob cultivo no país é encontrada na Região Sul, em particular no Rio Grande do Sul. Neste estado, a influência da colonização por grupos étnicos bastante diferenciados, como 
africanos, alemães, espanhóis, italianos, japoneses, poloneses e portugueses, promove a manutenção da diversidade genética e a ampliação da variabilidade genética em cada espécie.

Dentre as espécies cultivadas do gênero Cucurbita, C. pepo apresenta a maior variabilidade genética para características de fruto, como cor da casca, formato e tamanho. Inclui plantas com frutos comestíveis, conhecidas como mogangos ou abóboras, e plantas com frutos não comestíveis, conhecidos como abóboras ornamentais. Hoje, $C$. pepo está entre as hortaliças mais importantes economicamente em todo o mundo e é cultivada em quase todas as regiões de clima temperado e subtropical (Paris, 2001).

Na caracterização do germoplasma, um grande destaque vem sendo dado aos marcadores moleculares os quais permitem acessar uma ampla cobertura genômica, não dependem de condições ambientais e são extremamente úteis para estudos de genética populacional (Salla et al., 2002).

Dentre eles os marcadores microssatélites ou SSR (Simple Sequence Repeats) se destacam por serem amplamente aplicados em estudos genéticos e para a caracterização de espécies por serem abundantes no genoma, de natureza codominante, de fácil reprodução e interpretação dos dados. Desta forma os SSR são ferramentas ideais para uma ampla aplicação tanto em pesquisa básica quanto aplicada (Creste et al., 2003; Gong et al., 2008). Entre as aplicações desses marcadores, está estimar as distâncias genéticas entre indivíduos de uma mesma população e de populações diferentes e, a partir da matriz de distâncias, analisar a dispersão dos indivíduos, identificando a formação de grupos e a estrutura da população. Marcadores moleculares podem fornecer uma quantidade muito grande de informações a respeito da variabilidade e grau de relacionamento genético, tanto em populações naturais como em espécies sob cultivo (Cavalli, 2003). Tal informação é importante para identificar genes de interesse e acessar a variabilidade contida nos acessos conservados em Bancos de Germoplasma.

O Banco Ativo de Germoplasma de Cucurbitáceas da Embrapa Clima Temperado conta com 61 acessos de C. реро. Esses acessos são variedades crioulas cultivadas na Região Sul do país e fazem parte da cultura étnica regional, recebendo nomes específicos de acordo com características dos frutos, os quais são usados no preparo de diferentes pratos tradicionais, no artesanato e na ornamentação de ambientes (Priori et al., 2010).

O objetivo deste trabalho foi avaliar a variabilidade genética entre e dentro de variedades crioulas de $C$. pepo cultivadas no Rio Grande do Sul, com análise de marcadores microssatélites.

\section{MATERIAL E MÉTODOS}

Foi realizada uma busca no National Center for Biotechnology Information (www.ncbi.nlm.nih.gov) para selecionar iniciadores de síntese ou primers microssatélites já desenvolvidos para o gênero Cucurbita. Foram selecionados 40 pares de primers SSR desenhados para C. pepo, desenvolvidos pelo Applied Life Sciences the Institut of Biotechnology in Plant Production, Department for Agrobiotechnology of the BOKU-University of Natural Resources, na Austria (Tabela 1).

Foram analisados dez acessos de variedades crioulas de Cucurbita pepo que fazem parte do acervo do Banco Ativo de Germoplasma de Cucurbitáceas da Embrapa Clima Temperado. Estes acessos foram escolhidos por terem sido coletadas no Rio Grande do Sul e apresentarem diferentes formatos e tamanhos de fruto, além de cores e texturas da casca distintas. Foram analisados os acessos C148, C199, C222, C224, C260, C276, C290, C299, C377, C381 (Figura 1). O trabalho foi desenvolvido no Laboratório de Biologia Molecular da Embrapa Clima Temperado, em Pelotas (RS).

As plantas foram cultivadas em sacos plásticos de poliestireno preto preenchidos com substrato, em casa de vegetação. O DNA foi extraído das folhas jovens coletadas separadamente de cinco indivíduos de cada acesso. A extração foi realizada de acordo com o protocolo descrito por Ferreira \& Grattapaglia (1998). Os testes de qua- lidade e a quantificação do DNA foram feitos em gel de agarose $0,8 \%$, contendo $0,2 \mu \mathrm{g} / \mathrm{mL}$ de brometo de etídio. O DNA foi quantificado no gel por comparação com os padrões de bandas do marcador $\lambda$ DNA Hind III. Após a quantificação, o DNA foi diluído em TE para uma concentração de $25 \mathrm{ng} / \mu \mathrm{L}$.

As reações de amplificação de microssatélites (PCR-SSR) foram realizadas em volume final de reação de $25 \mu \mathrm{L}$ contendo, 10,2 $\mu \mathrm{l}$ de $\mathrm{H}_{2} \mathrm{O}, 1,4 \mu \mathrm{l}$ de $10 \mathrm{x}$ PCR Buffer, 1,6 $\mu$ lde $\mathrm{MgCl}_{2}$ (50 mM), $1,05 \mu 1$ de DNTPs $(12,5 \mathrm{mM}), 1.08 \mu \mathrm{lde}$ BSA $(10 \mathrm{mg} / \mu \mathrm{l}), 0,7 \mu \mathrm{l}$ de cada primer (Forward e Reverse) $10 \mu \mathrm{M}, 0,04 \mu \mathrm{de}$ Taq DNA Polimerase $(5 \mathrm{u} / \mu \mathrm{l})$ e $2,0 \mu \mathrm{l}$ de DNA (5ng/ $\mu 1)$. As amplificações foram realizadas em termociclador Applied Bio Systems Gene Amp PCR System 9700, programado para uma etapa inicial de desnaturação do DNA a $94^{\circ} \mathrm{C}$ por 4 min e 40 seg, seguido de 30 ciclos de 0,15 min a $94^{\circ} \mathrm{C}$ (desnaturação), 0,10 min a $60^{\circ} \mathrm{C}$ (anelamento) e $0,15 \mathrm{~min}$ a $72^{\circ} \mathrm{C}$. Por fim, uma etapa de $5 \mathrm{~min}$ a $72^{\circ} \mathrm{C}$. As temperaturas de anelamento variaram de $50-60^{\circ} \mathrm{C}$, conforme a temperatura do primer utilizado. Os fragmentos amplificados foram separados por eletroforese horizontal em gel de agarose (Invitrogen) 3,5\%, corado com brometo de etídio $(0,2 \mu \mathrm{g} / \mathrm{mL})$ e tampão TBE 1X (Tris-Borato $90 \mathrm{mM}$, EDTA $2 \mathrm{mM}$ ). Os géis foram visualizados em transiluminador de luz ultravioleta (UV). As imagens foram capturadas em câmara digital e armazenadas em computador para avaliação dos padrões de bandas. O marcador $1 \mathrm{~Kb}$ Plus DNA ladder foi utilizado como referência de peso molecular para estimar os tamanhos dos produtos da amplificação. $\mathrm{O}$ tamanho das bandas foi estimado através do programa computacional Bio - 1D Advanced - Vilber Lourmat SAS, 2006 (software de análise).

Os alelos amplificados foram identificados de acordo com o peso molecular das bandas geradas. Foi construída uma matriz multialélica para cada loco analisado, a partir da qual foi estimado: i) o conteúdo de informação de polimorfismo (PIC) de cada marcador foi estimado por meio da equação:

$$
\mathrm{PIC}=1-\sum p_{i^{2}} 1-\sum p_{i^{2}} \text { onde, }
$$


Tabela 1. Características dos locos de microssatélites avaliados em 50 indivíduos de Cucurbita pepo (characteristics of microsatellite loci evaluated in 50 individuals of Cucurbita pepo). Pelotas, Embrapa Clima Temperado, 2011.

\begin{tabular}{|c|c|c|c|c|c|c|c|}
\hline Nome* & Motif* & Forward / Reverse* & $\mathbf{P b}^{*}$ & Temp* & $\mathbf{A}$ & Amplitude & PIC \\
\hline CMTP46 & ag & ttccettctgcagagatgct/ccatgcgcataattgtatcg & 142 & 60 & 2 & $141-148$ & 0,67 \\
\hline CMTP33 & gaa & aatgcgtttgaacaaagctg/ggctgttaaaatttcctcgat & 171 & 58 & 3 & $173-183$ & 0,21 \\
\hline СМТР48 & ga & tttgcagtacgctgcagaac/ggatccttctcgtggtggta & 228 & 60 & na & na & na \\
\hline СМТР61 & tc & tttgcagtacgctgcagaac/ ggatcettctcgtggtggta & 118 & 60 & 2 & $113-108$ & 0,28 \\
\hline СМТР86 & cca & gctcttggacaagaatggtca/atggcttctggtggtttgtc & 133 & 60 & 2 & $152-135$ & 0,71 \\
\hline СМТР131 & $\operatorname{ccg}$ & gcacttgaatcttcgtcaac/cgagaaagaattaacgagca & 117 & 55 & 5 & $133-0,97$ & 0,53 \\
\hline CMTP132 & gat & ccatttccatttccatttca/ aggttagaaacagggggaatc & 151 & 58 & 2 & $151-143$ & 0,82 \\
\hline СМТР158 & gcag & ccgtagagatgtcagagacaagg/ agggatgctcatcacacctc & 134 & 60 & 3 & $140-121$ & 0,49 \\
\hline СМТР174 & $\mathrm{tc}+\mathrm{t}$ & gccggaaccagacttctc/ ccetccettcccattaaac & 176 & 58 & 2 & $186-175$ & 0,62 \\
\hline СМTP141 & tc & attcatgtcatactaccgacttc/ cggatttataagatggcaag & 135 & 55 & 3 & $169-118$ & 0,49 \\
\hline СМТР190 & ga & cggggaagagaggtttaggt/ cccatacattcccatataacacc & 210 & 59 & 5 & 293-173 & 0,64 \\
\hline CMTP182 & cgt & cacgaagatttgatggectta/ ggattgggatggtgaagatg & 138 & 60 & na & na & na \\
\hline СМТР204 & ag & agaaggaggagagcggaaag/ataagatcccaaccccaacc & 357 & 60 & 2 & $329-311$ & 0,88 \\
\hline СМТР210 & gtgtgc & gtggaagttactgcgattgg/ gcaaagaatgtcctcagcag & 117 & 58 & 3 & $125-107$ & 0,68 \\
\hline СМТР193 & ga & ggtgacggcaagaaaagcta/ gctgaccetctctccetctc & 186 & 60 & na & na & na \\
\hline СМТР201 & ct & aggagtggtgggctaatacg/ tgaaattgagggagggagag & 110 & 59 & 4 & $121-0,97$ & 0,65 \\
\hline СМТР247 & ga & gggtgtgttgaggattggtt/ atcacattttctccccacca & 123 & 60 & 3 & 137-119 & 0,53 \\
\hline СMTP17 & ct & actgctcaataaggcaagga/ aaacaagagtgcacaaacagg & 84 & 58 & 2 & $113-103$ & 0,39 \\
\hline СМТР107 & ttgga & cgatgatgaacaggaagacg/ tcacatccattcccetctct & 109 & 59 & 4 & $153-117$ & 0,75 \\
\hline СMTP62 & gt & gtgcccgtcagtcggaat /tgtcgacgaagatagcaatagca & 100 & 60 & 4 & $115-100$ & 0,42 \\
\hline СMTP58 & $\mathrm{ga}+\mathrm{t}$ & tcggagaaactcgacactcc/ tcccagcaccatcaggatac & 102 & 60 & 2 & 118-109 & 0,40 \\
\hline СМТР66 & gaa & acgacatgagggaagattcg/ ttcaatgccattcgcctac & 128 & 60 & 2 & $170-130$ & 0,52 \\
\hline СМТР84 & $\mathrm{tc}+\mathrm{t}$ & gcggtaacaggttgtttggt/ ccatcaggataccctacaaagg & 150 & 60 & 3 & $142-118$ & 0,83 \\
\hline СМТР97 & aag & ccacacaccaatcgttgaag /cgcagaatctcgaaacacaa & 166 & 60 & 3 & $166-150$ & 0,70 \\
\hline СМТР126 & ttc & acctcaaacccettttgtg/ ggaagaagaaggaggaggag & 117 & 57 & na & na & na \\
\hline СMTP120 & gaa & aaccggaacacctttatgacc/ttcaagaaggttccgaagga & 164 & 60 & 4 & $166-131$ & 0,71 \\
\hline СМТР130 & cgt & gcccatttctggagagatagta /gaggagagatgcagagcaac & 169 & 57 & na & na & na \\
\hline СМТР144 & cet & atggettccaagctcctctt/gtcggccatgagcttgag & 105 & 60 & 3 & $117-105$ & 0,50 \\
\hline СМТР133 & tc & tagagttcgatcaatgcaa /gttgatacttcaaccacgtt & 113 & 57 & 4 & $152-112$ & 0,50 \\
\hline СMTP187 & $\mathrm{cag}+\mathrm{caa}$ & aacaatcctcgcctcaaatc/atgaaaatgggaagccagag & 189 & 60 & 3 & $189-131$ & 0,37 \\
\hline СМТР219 & tc & ttcatcatcgtcagcaaagc /gcacatgcagcactctgact & 117 & 60 & na & na & na \\
\hline СМТР207 & $\mathrm{cg}$ & gacgaacgaagcatgttgag /ggtcagcaaggtcagaaagg & 156 & 60 & 3 & $132-105$ & 0,31 \\
\hline СМТР224 & caa & caccgacgactccatcatc/cttcttgtccccaaaatcaca & 151 & 60 & 3 & $163-122$ & 0,49 \\
\hline СМТР261 & gaa + cat & aaatgccagcccaaatcat/gatggctgccacttcctcta & 187 & 60 & 2 & $231-187$ & 0,42 \\
\hline СМТР68 & tc + ggcttc & cacacccatttcattttgacc/ attgattgggacgtgaggaa & 180 & 60 & 4 & $195-171$ & 0,20 \\
\hline СМТР125 & tc & cttgttccgcagcatcag/ agtgagagggagacgcaaag & 115 & 59 & 3 & $122-109$ & 0,64 \\
\hline СМТР138 & $\mathrm{T}$ & aaaggtttccacatccttg/ gaaaaggaaaaagtgttcaaag & 103 & 55 & 2 & $110-103$ & 0,67 \\
\hline СМТР209 & $\mathrm{gtt}$ & tcactttacaaccagaagctga/ cactttgctgctcatccac & 116 & 57 & 3 & $124-110$ & 0,42 \\
\hline СМТР83 & tc & tgaccattttgcagattgaga /cttccggagacgaaagagtc & 112 & 59 & 2 & $119-111$ & 0,45 \\
\hline СMTP127 & cacgcc & ttcctctgtttccgtcaatg/ cacaaaaggggtttgaggtt & 112 & 58 & 3 & $125-110$ & 0,55 \\
\hline
\end{tabular}

$\mathrm{pb}=$ pares de base, temp = temperatura de anelamento, $\mathrm{A}=$ número de alelos, na= não amplificou (*Informações dos $\mathrm{SSR}$ fornecidas por Applied Life Sciences the Institut of Biotechnology in Plant Production, Department for Agro biotechnology of the BOKU-University of Natural Resources, Austria) (bp=base pairs, temp= annealing temperature, A= number of alleles, na= not amplified [ ${ }^{*}$ Information provided the SSR by Applied Life Sciences the Institut of Biotechnology in Plant Production, Department for Agro biotechnology of the BOKUUniversity of Natural Resources, Austria)]. 
pi é a frequência ao quadrado do alelo i, ii) a distância genética entre os acessos foi estimada, utilizando o software NTSYS-PC, versão 2.1 (Rohlf, 2000), com base na distância de Rogers Modificado (Wright, 1978) conforme a equação:

$\mathrm{DW}=\frac{1}{\sqrt{2 m}} \sqrt{\sum_{i=1}^{m} \sum_{j=1}^{n j}\left(\mathrm{p}_{\mathrm{ij}}-\mathrm{q}_{\mathrm{ij}}\right)^{2}}$

onde, $\mathrm{p}_{\mathrm{ij}}$ e $\mathrm{q}_{\mathrm{ij}}$ correspondem às frequências do alelo j no loco i nos dois genótipos em consideração, $n_{i}$ é o número de alelos do loco i, e m se refere ao número de locos.

A partir da matriz original gerada com base na leitura dos géis de dados codominantes, foi estimada a distância euclidiana entre os indivíduos. Com base no quadrado da distância euclidiana foram calculadas as estimativas da variabilidade genética entre os acessos procedentes do mesmo município, dentro de acessos e entre acessos procedentes de diferentes municípios, com análise molecular da variância (AMOVA) utilizando o programa computacional Genes. $\mathrm{O}$ valor $\mathrm{F}_{\mathrm{st}}$, que representa a distância genética entre os acessos, foi utilizado para comparar a variação genética entre as dez populações avaliadas. Para testar a significância dos resultados da AMOVA foi utilizado o método não-paramétrico de permutações (Excoffier et al., 1992).

Com base na matriz de distância genética foi construído um dendrograma, por meio do método de agrupamento da distância média UPGMA (Unweighted Pair Group Method Using Arithmetic Average). O ajuste entre a matriz de dissimilaridade e o dendrograma foi estimado pelo coeficiente de correlação cofenética (r), conforme Sokal \& Rohlf (1962), utilizando o programa computacional NTSYS-PC (Rohlf, 2000). Esse coeficiente traduz a relação momento-produto, calculado entre os elementos da matriz original e os da matriz cofenética, resultante da simplificação proporcionada pelo método de agrupamento, depois da construção do dendrograma. Valores de (r) acima de 0,8 indicam boa representatividade entre as distâncias (Bussad et al., 1990). A estabilidade dos agrupamentos foi computada por meio da análise de Bootstraping com
1000 replicações, com a utilização do programa computacional Winboot (Yap \& Nelson, 1996).

\section{RESULTADOS E DISCUSSÃO}

Entre os 40 locos SSR analisados nos indivíduos amostrados de Cucurbita pepo, 34 amplificaram e foram identificados um total de 100 alelos, com variação de um a cinco alelos por loco, com média geral de três alelos por loco analisado (Tabela 1). As frequências alélicas variaram de 0,04 a 1,0 com média geral de 0,35. O tamanho dos alelos encontrados variou de 97 a 329 $\mathrm{pb}$, conforme o esperado.

Os 100 alelos gerados a partir dos 34 locos SSR foram suficientes para discriminar os cinquenta indivíduos das dez variedades crioulas de C. pepo (Figura 2). Para os locos SSR analisados neste trabalho, o conteúdo de informação de polimorfismo (PIC) variou de 0,20 a 0,88 com média geral de 0,52 entre todos os acessos analisados. Os locos que apresentaram maior informação de polimorfismo foram CMTP204, CMTP84, CMTP132, CMTP107 е CMTP120, com valores, respectivamente, de 0,$88 ; 0,83 ; 0,82 ; 0,75$ e 0,71 (Tabela 1). Dentre os 34 locos SSR, 29 foram polimórficos $(85,2 \%)$, evidenciando variabilidade genética entre os acessos de $C$. pepo analisados, confirmando dados de caracterização morfológica já realizada com a espécie (Heiden et al., 2007). Essas observações estão de acor- do com resultados obtidos por outros autores. Paris (2001) relatou uma grande variabilidade genética expressa em características vegetativas, reprodutivas e de frutos em cultivares de polinização aberta de $C$. pepo. A caracterização molecular de 69 acessos de C. pepo, incluindo variedades crioulas e cultivares comerciais, usando 11 combinações de primers SRAP (Sequence Related Amplified Polymorphism), identificou um total de 88 fragmentos, sendo que 64 foram polimórficos $(72,7 \%)$, mostrando a ampla variabilidade genética existente nesta espécie (Ferriol et al., 2003). Os resultados obtidos também concordam com a alta variabilidade genética relatada para esta espécie por Gong et al. (2012), os quais avaliaram o polimorfismo de 134 locos SSR e 4 locos SCAR (Sequenced Characterized Amplified Region) em 104 acessos de $C$. pepo, o que produziu 418 alelos com média de 3 alelos por loco.

Um alto grau de variabilidade genética entre acessos de variedades crioulas também foi observado em outras espécies de Cucurbita. A caracterização molecular de 74 variedades crioulas de C. moschata cultivadas na China, usando 9 combinações de primers AFLP (Amplified Fragment Lenght Polymorphism), produziu 500 fragmentos, dos quais $75,57 \%$ foram polimórficos (Wu et al., 2011). Em $C$. moschata, o grau de polimorfismo detectado com marcadores AFLP foi maior do que aquele obtido com marcadores RAPD (Random Amplified Polymorphic

Tabela 2. Distribuição da variabilidade genética de Cucurbita pepo com base na análise molecular da variância (AMOVA) (distribution of genetic variability of Cucurbita pepo based on the analysis of molecular variance (AMOVA)). Pelotas, Embrapa Clima Temperado, 2011.

\begin{tabular}{lcccc}
\hline Fonte de variação & GL & SQ & $\begin{array}{c}\text { Componentes } \\
\text { da variância }\end{array}$ & $\begin{array}{c}\text { Variação } \\
\text { total (\%) }\end{array}$ \\
\hline $\begin{array}{l}\text { Entre acessos procedentes do } \\
\text { mesmo município }\end{array}$ & 9 & 575,78 & 10,97 & $54,60^{*}$ \\
$\begin{array}{l}\text { Dentro dos acessos } \\
\begin{array}{l}\text { Entre acessos de diferentes } \\
\text { municípios }\end{array}\end{array}$ & 40 & 364,80 & 9,12 & $45,39^{*}$ \\
Total & 3 & 231,34 & 5,60 & $26,67^{\text {ns }}$ \\
\hline
\end{tabular}

*Valores significativos ao nível de $1 \%$ de probabilidade; $\mathrm{SQ}=$ soma de quadrados; $\mathrm{GL}=$ grau de liberdade; $\mathrm{ns}=$ valor não significativo (*values significant at $1 \%$; $\mathrm{SQ}=$ sum of squares; $\mathrm{GL}=$ degree of freedom; $\mathrm{ns}=$ value not significant $)$. 
Tabela 3. Análise comparativa $2 \times 2$ entre acessos de Cucurbita pepo obtidas por meio da AMOVA; a porcentagem da variação molecular total existente entre os acessos $\left(\mathrm{F}_{\mathrm{st}}\right)$ é a medida da distância genética entre os acessos (comparative analysis $2 \mathrm{x} 2$ between Cucurbita pepo accessions obtained by AMOVA; the percentage of total molecular variation between accessions (Fst) is a measure of genetic distance among accessions). Pelotas, Embrapa Clima Temperado, 2011.

\begin{tabular}{lcccccccccc}
\hline Acessos & C148 & C260 & C276 & C290 & C381 & C199 & C222 & C224 & C299 & C377 \\
\hline C148 & - & $55,99^{* *}$ & $56,48^{* *}$ & $51,53^{* *}$ & $59,81^{* *}$ & $47,93^{\text {ns }}$ & $42,69^{\text {ns }}$ & $49,86^{\text {ns }}$ & $60,91^{* *}$ & $54,82^{* *}$ \\
C260 & & - & $54,75^{* *}$ & $58,25^{* *}$ & $62,89^{* *}$ & $52,51^{* *}$ & $46,49^{\text {ns }}$ & $36,23^{\text {ns }}$ & $63,56^{* *}$ & $55,99^{* *}$ \\
C276 & & & - & $58,32^{* *}$ & $58,84^{* *}$ & $58,76^{* *}$ & $58,76^{* *}$ & $52,33^{* *}$ & $52,90^{* *}$ & $53,59^{* *}$ \\
C290 & & & & - & $50,23^{* *}$ & $64,48^{* *}$ & $55,10^{* *}$ & $52,63^{* *}$ & $47,91^{\text {ns }}$ & $53,18^{* *}$ \\
C381 & & & & & - & $65,31^{* *}$ & $60,16^{* *}$ & $55,70^{* *}$ & $57,73^{* *}$ & $53,20^{* *}$ \\
C199 & & & & & & - & $51,82^{* *}$ & $41,65^{\text {ns }}$ & $63,16^{* *}$ & $61,66^{* *}$ \\
C222 & & & & & & & - & $35,13^{\text {ns }}$ & $64,77^{* *}$ & $56,07^{* *}$ \\
C224 & & & & & & & & - & $52,50^{* *}$ & $49,53^{\text {ns }}$ \\
C299 & & & & & & & & & - & $47,32^{\text {ns }}$ \\
C377 & & & & & & & & & & - \\
\hline
\end{tabular}

*valores significativos ao nível de 5\% de probabilidade; ${ }^{* *}$ valores significativos ao nível de $1 \%$ de probabilidade; ${ }^{\text {ns }}$ valores não significativos (*values significant at $5 \% ; * *$ values significant at $1 \% ;{ }^{\text {ns }}$ not significant values).

DNA) e SRAP (Gwanama et al., 2000; Ferriol et al., 2004).

Na matriz de distâncias genéticas entre os indivíduos de C. pepo, foram obtidos valores altamente variáveis, apresentando distância mínima de 0,29 e distância máxima de 0,80 . A distância mínima foi observada entre dois indivíduos do acesso C199, o qual é uma variedade crioula de mogango, cujo fruto, de casca bastante dura e polpa fibrosa é usado na alimentação. Por sua vez, a maior distância genética foi observada entre indivíduos dos acessos C381 (uma variedade crioula de abóbora-estrela) e C276 (uma variedade crioula de abóbora ornamental). A partir da matriz multialélica foi estimada a variância genética pela análise molecular da variância (AMOVA) entre os acessos procedentes do mesmo município, dentro de acessos e entre acessos procedentes de diferentes municípios (Tabela 2). $\mathrm{O}$ padrão de variabilidade genética encontrado indicou que a maior parte da variação molecular $(54,60 \%)$ ocorre entre os acessos provenientes do mesmo município. No entanto, uma quantidade significativa $(45,39 \%)$ também foi atribuída a diferenças dentro dos acessos. A variância genética entre os municípios onde os acessos foram coletados não foi significativa, indicando que não ocorreu subdivisão de populações em função do local de coleta. Estes resultados foram semelhantes aos relatados com outra cucurbitácea por Mujaju et al. (2010), ao analisar oito variedades crioulas de melancia (Citrullus lanatus) cultivadas no Zimbabwe, com nove pares de primers SSR e dez primers RAPD. A AMOVA indicou que a maior parte da variância genética $(60,9 \%)$ também estava entre os acessos, com uma variação menor dentro de cada acesso $(39,1 \%)$.

Isso se explica pelo fato de que os agricultores geralmente cultivam mais de uma variedade crioula de Cucurbita na mesma propriedade, sem um distanciamento geográfico entre elas. Como são plantas alógamas, essa proximidade favorece o fluxo gênico entre essas variedades, incrementando assim a variabilidade genética entre e dentro das populações. Por sua vez, o agricultor pratica seleção recorrente com base na morfologia dos frutos, sempre buscando um formato que considera ideal, o que faz com que se mantenha certa variabilidade genética dentro de cada variedade crioula. A variabilidade apresentada dentro dos acessos avaliados neste trabalho, por exibirem valor alto e próximo ao encontrado entre os acessos, está de acordo com a afirmação de Loveless \& Hamrick (1984) de que uma alta variabilidade dentro das populações é típica de espécies que apresentam mecanismos eficientes de dispersão de pólen, como é o caso das cucurbitáceas.

A distância genética entre os dez acessos de C. pepo foi estimada a partir de comparações estabelecidas entre cada dupla de acessos. Foram verificadas diferenças significativas entre 35 das 45 comparações realizadas (Tabela 3 ). As condições de manejo adotadas pelos agricultores no sistema de cultivo tradicional utilizado têm sido eficientes para preservar a riqueza do germoplasma no local onde estes acessos são selecionados e manter a variabilidade genética destas variedades crioulas. No Sul do Brasil é comum o intercâmbio de sementes de variedades crioulas pelos agricultores, tanto em feiras de trocas de sementes como de maneira informal, entre vizinhos e parentes (Rodrigues et al., 2009; Priori, 2011)

O dendrograma gerado com base na distância média entre os 50 indivíduos $(0,63)$ evidenciou a formação de cinco grupos distintos (Figura 2). O coeficiente de correlação cofenética entre o dendrograma e a matriz de distância genética foi elevado $(r=0,86)$. Os grupos formados pelas dez variedades crioulas avaliadas não tiveram relação com as características morfológicas de fruto, pois acessos morfologicamente semelhantes não ficaram no mesmo grupo e alguns grupos reuniram diferentes acessos com frutos bastante distintos. Dois grupos foram formados por apenas um acesso, o grupo I, com C381 (abóbora-estrela), e o grupo $\mathrm{V}$, com C148 (poronguinho ornamental). Os grupos II e III reuniram 

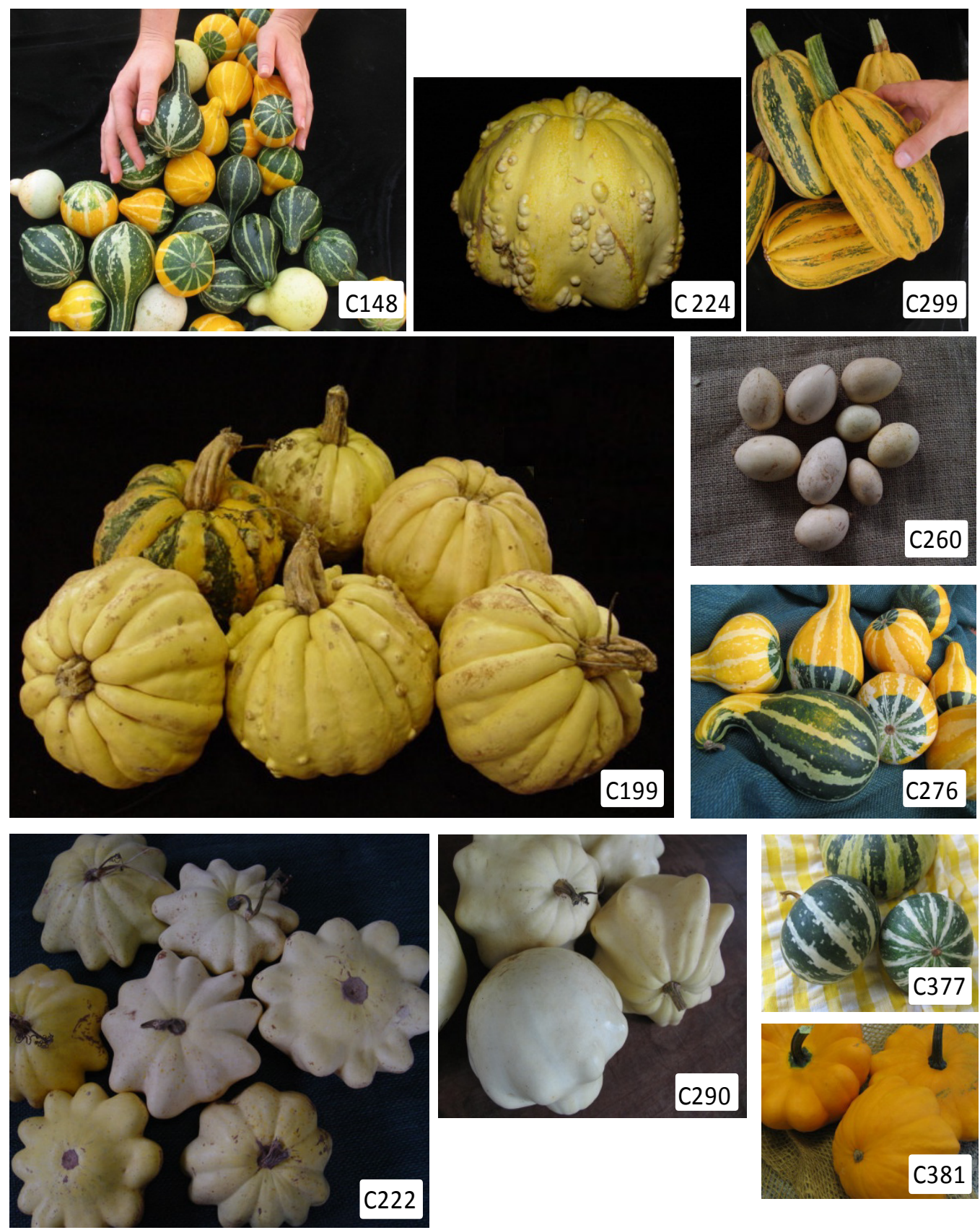

Figura 1. Variabilidade genética em frutos de variedades crioulas de Cucurbita pepo $(\mathrm{C} 148=$ poronguinho, C260 $=$ abóbora-ovo, $\mathrm{C} 276=$ abóbora, C290= abóbora-estrela, C381= abóbora-estrela; C199= mogango amarelo; C222= abóbora-estrela, C224= mogango verrucoso; $\mathrm{C} 229=$ moganguinho alongado, $\mathrm{C} 377=$ abobrinha ornamental) (genetic variability of fruits of $C$ ucurbita pepo landraces $(\mathrm{C} 148=$ poronguinho, C260= abóbora-ovo, C276= abóbora, C290= abóbora-estrela, C381= abóbora-estrela, C199= mogango-amarelo, C222= abóbora-estrela, C224= mogango verrucoso, C229= moganguinho, C377= abobrinha ornamental). Pelotas, Embrapa Clima Temperado, 2011.

dois acessos cada, ficando, respectivamente, C299 (mogango) e C377 (abobrinha ornamental), e C276 (abóbora) e C290 (abóbora-estrela). Por sua vez, o grupo IV reuniu quatro acessos: C199 (mogango), C222 (abóbora-estrela), C224 (mogango verrucoso) e C260 (abóbora-ovo). O fato de acessos mor- fologicamente semelhantes não terem ficado no mesmo grupo indica que os primers usados nas análises amplificaram regiões de microssatélites aleatórias do genoma. É importante ressaltar que todos os indivíduos do mesmo acesso permaneceram no mesmo grupo, indicando maior variabilidade genética entre acessos do que dentro dos acessos, o que está de acordo com os resultados da AMOVA.

Os resultados encontrados neste trabalho para as variedades crioulas de C. pepo cultivadas no Sul do Brasil são semelhantes àqueles relatados por Ramos (2003), ao quantificar a variabi- 


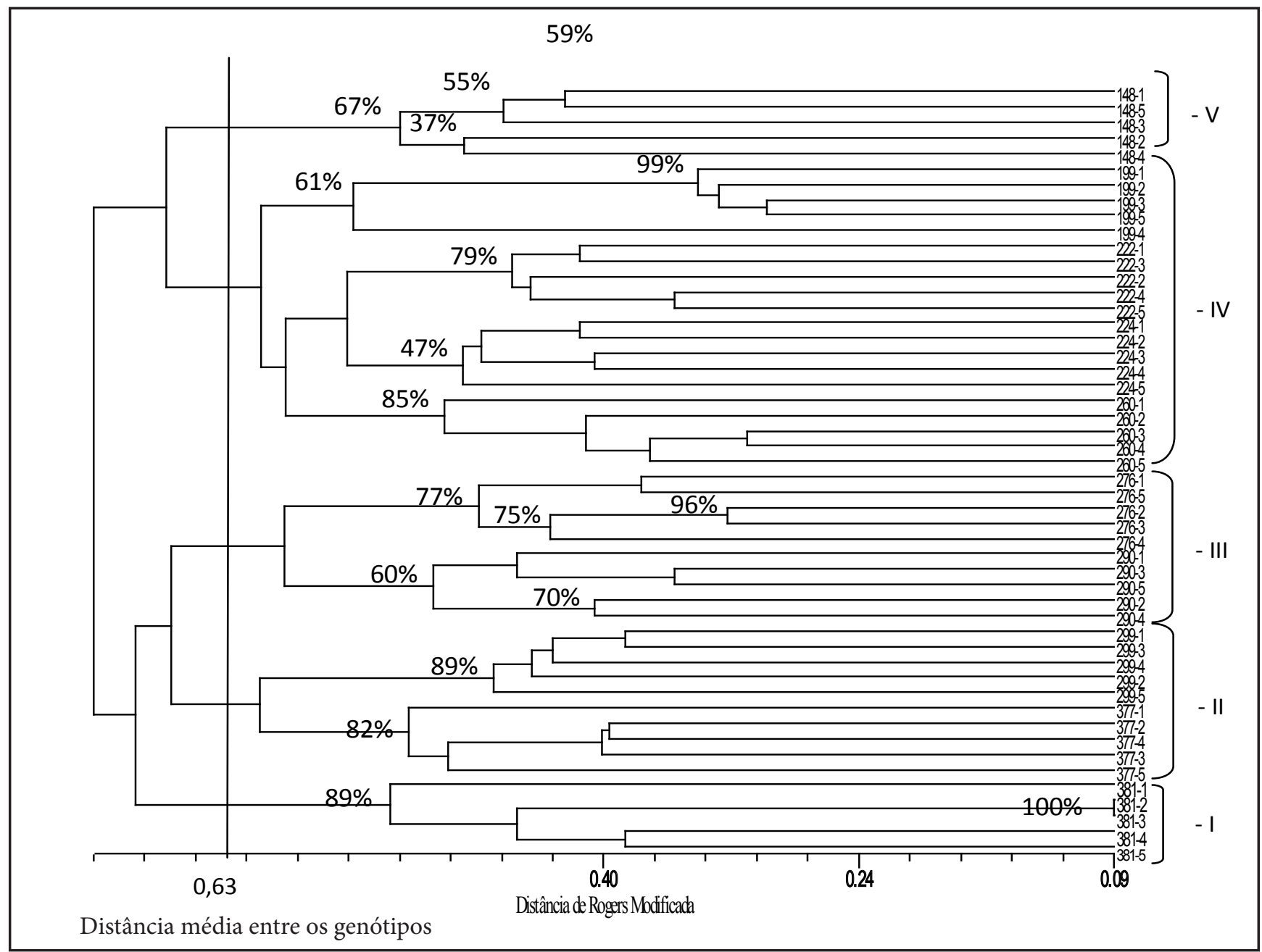

Figura 2. Dendrograma resultante da análise de 34 locos SSR em 50 indivíduos de Cucurbita pepo, gerado pelo método de agrupamento UPGMA, com base na matriz de distância genética obtida pela Distância de Rogers modificada; os valores encontrados nos grupos indicam o percentual de vezes que os genótipos agrupam juntos em 1000 ciclos de análise de bootstraping; O valor do coeficiente de correlação cofenética (r) é de 0,86 (dendrogram resulting from the analysis of 50 individuals of Cucurbita pepo, generated by the UPGMA clustering method based on genetic distance matrix obtained using the modified Rogers distance, based on analysis of 34 SSR loci; the values found in the groups indicate the percentage of times that the genotypes grouped together in 1000 cycles bootstraping analysis; the value of cophenetic correlation coefficient (r) is 0.86). Pelotas, Embrapa Clima Temperado, 2011.

lidade genética de variedades crioulas de C. moschata cultivadas no Nordeste brasileiro, com análise de marcadores moleculares do tipo AFLP. Naquele trabalho, foi evidenciada boa discriminação entre os acessos, sugerindo que a seleção praticada pelos agricultores foi eficaz em diferenciar os padrões de variabilidade, sendo que as relações genéticas quantificadas pela análise de AFLP refletiram a intensa troca de sementes entre os agricultores em diversas partes da Região Nordeste.

Existe grande variabilidade genética em variedades crioulas de C. pepo cultivadas no Rio Grande do Sul. Não ocorre subdivisão de populações em função do local de coleta. A maior proporção da variabilidade genética encontra-se distribuída entre as diferentes variedades crioulas, embora também exista variabilidade genética dentro das populações.

\section{AGRADECIMENTOS}

À CAPES, pela bolsa de mestrado concedida ao primeiro autor.

\section{REFERÊNCIAS}

BUSSAD WO; MIAZAKI ES; ANDRADE DF 1990. Introdução à análise de agrupamentos. São Paulo: Associação Brasileira de Estatística, 105p.
CAVALLI SS. 2003. Polimorfismos moleculares. In: Genética e evolução vegetal. Porto Alegre: UFRGS, 311-332.

CRESTE SJ; TULMANN NETO A; SILVA SO; FIGUEIRAA. 2003. Genetic characterization of banana cultivars (Musa spp.) from Brazil using microssatelite markers. Euphytica 132: 259-268.

EXCOFFIER L; SMOUSE PE; QUATTRO JM. 1992. Analysis of molecular variance inferred from metric distances among DNA haplotypes: Application to human mitochondrial DNA restriction data. Genetics 131: 479-491.

FERREIRA M; GRATTAPAGLIA D. 1998. Introdução ao uso de marcadores moleculares em análise genética. Brasília: EMBRAPA CENARGEN. 220p.

FERRIOL M; PICÓ B; NUEZ F. 2003. Genetic diversity of a germplasm collection of Cucurbita pepo using SRAP and AFLP markers. Theoretical and Applied Genetics 
107: 271-282

FERRIOL M; PICÓ B; CÓRDOVA PF; NUEZ F. 2004. Molecular diversity of a germplasm collection of squash (Cucurbita moschata) determined by SRAP and AFLP markers. Crop Science 44: 653-664.

GONG L; STIFT G; KOFLER R; PACHNER M; LELLEY T. 2008. Microsatellites for the genus Cucurbita and an SSR-based genetic linkage map of Cucurbita pepo L. Theoretical and Applied Genetics 117: 37-48.

GONG L; PARIS HS; NEE MH; STIFT G; PACHNER M; VOLLMANN J; LELLEY T. 2012. Genetic relationships and evolution in Cucurbita pepo (pumpkin, squash, gourd) as revealed by simple sequence repeat polymorphisms. Theoretical and Applied Genetics 124: 875-891.

GWANAMA C; LABUSCHAGNE MT; BOTHA AM. 2000. Analysis of genetic variation in Cucurbita moschata by random amplified polymorphic DNA (RAPD) markers. Euphytica 113: 19-24.

HEIDEN G; BARBIERI RL; NEITZKE RS. 2007. Chave para identificação das espécies de abóboras (Cucurbita, Cucurbitaceae) cultivadas no Brasil. Pelotas: Embrapa Clima Temperado. 31p.

LOVELESS MD; HAMRICK JL. 1984. Ecological determinants of genetic structure in plant populations. Annual Review of Ecology and Systematics 15: 68-95.

MUJAJU C; SEHIC J; WERLEMARK G;
GARKAVA-GUSTAVSSON L; FATIH M; NYBOM H. 2010. Genetic diversity in watermelon (Citrullus lanatus) landraces from Zimbabwe revealed by RAPD and SSR markers. Hereditas 147: 142-153.

PARIS HS. 2001. History of the cultivar-groups of Cucurbita pepo. Horticultural Reviews 25: 71-170.

PRIORI D; BARBIERI RL; NEITZKE RS; VASCONCELOS CS; OLIVEIRA CS; MISTURA CC; COSTA FA. 2010. Acervo do Banco Ativo de Germoplasma de Cucurbitáceas da Embrapa Clima Temperado - 2002 a 2010. Pelotas: Embrapa Clima Temperado. $37 \mathrm{p}$.

PRIORI D. 2011. Caracterização molecular de recursos genéticos de Cucurbita argyrosperma, Cucurbita ficifolia e Cucurbita pepo. Pelotas: UFPEL. 78p (Dissertação mestrado).

RODRIGUES WF; BARBIERI RL; GOMES JCC; CORREA IV; BEVILAQUA GA; ANTUNES IF; LEITE DL; CASTRO LAS; SILVA SDA. 2009. Agrobiodiversidade. In: SCHÄFER AE; LANZER R; PEREIRA R. Atlas socioambiental dos municípios de Mostardas, Tavares, São José do Norte, Santa Vitória do Palmar. Caxias do Sul: UCS. 251-259.

RAMOS SRR. 2003. Divergência genética baseada em marcadores moleculares AFLP e indicação de coleção nuclear de Cucurbita moschata para o Nordeste do Brasil. Campos dos Goytacazes: UENF. 102 p. (Tese doutorado).

RAMOS SRR; QUEIROZ MA. 2005. Recursos genéticos de abóbora no Nordeste brasileiro. In: MOURA MCCL. Recursos genéticos de hortaliças: riquezas naturais. São Luís: Instituto Interamericano de Cooperação para a Agricultura, 99-116.

ROHLF FJ NTSYS-pc. 2000. Numerical taxonomy and multivariate analysis system. Version 2.1. New York: Exeter, Software.

SALLA MFS; RUAS CF; RUAS PM; CARPENTIERI-PÍPOLO V. 2002. Uso de marcadores moleculares na análise da variabilidade genética em acerola (Malpighia emarginata D.C.). Revista Brasileira de Fruticultura 24: 15-22.

SOKAL RR; ROHLF FJ. 1962. The comparison of dendrograms by objective methods. Taxon 11: $33-40$.

WRIGHT S. 1978. Evolution and genetics of populations - Variability within and among natural populations. Chicago: The University of Chicago Press. 590p.

WU J; CHANG Z; WU Q; ZHAN H; XIE S. 2011. Molecular diversity of Chinese Cucurbita moschata germplasm collections detected by AFLP markers. Scientia Horticulturae 128: 7-13.

YAP IV; NELSON RJ. 1996. Winboot: a program for performing bootstrap analysis of binary data to determine the confidence limits of UPGMA-based dendrograms. Manila: IRRI, 22p. 